\title{
Study on Tutorial System Training Mode of Local Application-Oriented Higher Institutions
}

\author{
Lin Chaowen ${ }^{1, a}$, Wang $\mathrm{Ju}^{2, \mathrm{~b}}$ \\ ${ }^{1}$ Xuzhou Institute of Technology, Xuzhou 221111, China \\ ${ }^{2}$ Xuzhou Institute of Technology, Xuzhou 221111, China \\ a49782002@qq.com, b31757155@qq.com
}

Keywords: Local application-oriented higher institutions, Tutorial system, Reformation.

\begin{abstract}
The problems of teacher shortage, funds lack for running a school, cultural conflict, imperfect management mechanism and evaluation system were analyzed when the tutorial system were implemented in local colleges. In addition, based on the characteristics of local application-oriented higher institutions, some measures had been put forward, such as revising the concept of university education, modernizing, localization and school-based transformation to promote the effective implementation of the undergraduate tutorial system.
\end{abstract}

\section{Introduction}

The tutorial system originated from the traditional guidance system of Oxford and Cambridge, and organically combined the credit system of United States, which plays a vital role in the training of the British ordinary university. In order to improve the quality and connotation of the training of university talents under the background of the "Popularization of Higher Education", a group of key universities in China, such as Beijing University and Zhejiang University, have introduced the tutorial system education model since 1999. In the practice, due to the differences in the educational system and the different understanding of the connotation of the tutor system, various colleges and universities have formed their own characteristic implementation schemes of the tutorial system for undergraduates, which promoted the cultivation of talents in colleges and universities in our country, but also produced many urgent problems.

The local application-oriented higher institutions account for about $86 \%$ of the total number of undergraduate universities in China. Compared with the research colleges or the key colleges, these colleges have typical local characteristics, which usually emphasize "localism" and "application" in the direction of undergraduate cultivation. However, with the gradual implementation of the "Major National Strategies of 2025", "Internet +", "Mass Entrepreneurship" and "the Belt and Road", our country is in urgent need of a large number of applied, complex and innovative talents that can serve the production line to meet the requirements of economic restructuring and industrial upgrading [1]. This puts forward new requirements for talents training in local application-oriented higher institutions. Therefore, the local application-oriented higher institutions should actively introduce the undergraduate guidance system, transform the educational concept, and pay more attention to the cultivation of students' learning ability, practical ability and innovative ability in teaching.

\section{Difficulties in the implementation of the undergraduate tutorial system}

Due to the objective conditions of local application-oriented higher institutions, there are still some outstanding problems in the implementation of undergraduate tutorial system Training Mode. At the same time, teachers and students' understanding of tutorial system is not comprehensive enough, the degree of recognition and enthusiasm for the system is not high, it is difficult to put into practice in the implementation, the content of the tutor's work is not clear, the relationship between teachers and students to alienate, and the implementation effect is difficult to be evaluated. These problems make it more difficult to implement the tutorial system in local application-oriented higher institutions. 


\subsection{Shortage of teachers}

The number of tutors is an important factor to influence the implementation effect of the undergraduate tutorial system. To give full play to the teaching effect of the undergraduate tutorial system, a lower ratio of tutors is necessary. In the early period of Oxford University, there were no more than one-to-one individual tutors, even though the number of tutors was less than one-to-five. Ivy universities, such as Stanford University and Princeton University, also had consistently low ratios of 1:3 to 1:6. In China, there is a congenital shortage of teachers in the local undergraduate colleges and universities. According to the National Bulletin on Educational Development, the number of full-time teachers in our local colleges and universities in 2016 was 1,090,669, while the number of students in our colleges and universities was $25,116,528$, with a ratio of students to students of 1:23. In the same period, the number of full-time teachers in colleges and universities affiliated to the central government was 199,787, and the number of students in schools was 184,1905, with a ratio of 1:9.2. The former faculty was far lower than the latter, and the larger teacher student ratio made it difficult for the undergraduate tutorial system to be promoted in a comprehensive way.

\subsection{Insufficient funds for running schools}

Undergraduate tutorial system is based on a low ratio of teachers to students, which is essentially a high cost system [2]. However, the scale of higher education in our country is large, and the high cost tutorial system is in contradiction with the strained resource conditions of colleges and universities, which is more prominent in local colleges. According to the National Statistical Notice on the Implementation of Education Funding in 2016, the average public budget for general and higher education students nationwide was 8,067 yuan, a decrease of 2.57 percent from 2015. Moreover, there were large differences in the average budget of students in different regions. For example, the highest area in 2016 was Beijing, with a budget of 29,346 yuan, while the lowest area was Shandong Province, with a budget of 3,258 yuan, which was nearly eight times different from Beijing. So, it can be concluded that the educational expenses of local colleges and universities, which are responsible for the main tasks of higher education in our country, are far lower than those of the institutions affiliated with the central government. In many local universities, the average public budget is less than the national average, and many local colleges and universities have to lower the cost of running schools, even at the expense of education quality [3].

\subsection{Cultural dilemma}

The undergraduate tutorial system is the product of western culture, especially the western education culture. In the western education culture, the concept of equality between teachers and students, and teaching freedom is very prominent. Under the concept of free education, exploring and teaching general knowledge is taken as the sacred mission of the University, free reason and character formation is taken as the purpose of education, the free education is taken as the only process and goal of the development of students mind in Oxford University. From the "Midwife Teaching" of Socrates to the freedom of teaching in Berlin University to the Democratic educational thought represented by Dewey, all universities emphasized the equality of teacher-student relations, the interaction and exchange between the teaching and students, and the initiative, reflection and self-consciousness of students [4].

In China, the educational culture accumulated over thousands of years has a totally different value pursuit from the western educational culture of equality and freedom. In this culture, the grade difference and distance between teachers and students are very prominent. It is obvious that the undergraduate tutorial system has a sharp contradiction with our traditional cultural concept. Not only some teachers are difficult to understand and accept this new thing, but many tutors have difficulty in mastering effective work methods in the process of work [5]. The close interaction between teachers and students that colleges and universities expect is not widespread. 


\subsection{Dilemma of management mechanism and evaluation system}

In the western undergraduate tutorial system, "the relationship between tutors and students is often loose, free, similar to learning partners, with greater randomness, no mandatory and restrictive" [6], which makes up for the shortcomings of the traditional teaching system. So, it is a personalized and living education system. The teaching time and place of the undergraduate tutorial system is not fixed, the instruction content and the method are also random. The relationship between the students and the tutor is more based on the relationship and the good personal relationship. However, the traditional educational management in Chinese universities depends on the rational management of the hierarchical system, it makes strict and perfect teaching system according to the target of talents training, clear regulations on teaching behavior, and through the administrative authority of the hierarchical system to promote, inspection and supervision. Obviously, the way of management is aimed at a unified, clearly defined, visual, measurable and countable teaching behavior, which is very hard for undergraduate tutorial system characterized by individuation and life. The effectiveness of undergraduate tutorial system depends largely on the sense of responsibility, personality, temperament and even opportunities of tutors and students. Therefore, in this sense, the current university education management system is almost helpless for the management of undergraduate tutorial system.

\section{Reform measures to implement the undergraduate tutorial system}

Facing the dilemma of the implementation of the undergraduate tutorial system and the urgent need of the development of higher education for the reform of the educational model, it is necessary to carry out an in-depth study on the application of the undergraduate tutorial system in the local application-oriented higher institutions based on the characteristics of themselves to find an effective application model through practical innovation.

\subsection{Reshaping the university education concept and maintaining the basic characteristics of the tutorial system}

The university is a self-management of the academic community, a critical force of society and a pioneer of reform, which is the strongest and most influential university concept in the world's top-class universities such as Oxford and Cambridge. However, local application-oriented higher institutions in our country tend to focus too much on skills training and knowledge accumulation, so it is difficult to promote the equal exchange and free exploration of knowledge and truth. The effect of undergraduate tutorial system is not good, not because of the lack of high quality teachers, but the environment and policy orientation. Therefore, we must start from the concept of free education and the core goal of cultivating students 'critical thinking, reposition and restore the original nature of the undergraduate teaching system, so as to safeguard the free rights of both teachers and students, stimulate the potential and talents of both teachers and students, and ensure the core functions of the teaching system in the training of talents [7].

\subsection{Modernizing, localization and school-based transformation of undergraduate tutorial system}

The undergraduate tutorial system is derived from the elite education in the West. So, in order to adapt it to the traditional Chinese educational culture, the popularization of higher education and the traditional management system in colleges and universities, local colleges and universities should actively implement undergraduate tutorial system, make scientific orientation and reform their modernization, localization and school-based transformation.

Establishing a reasonable tutors evaluation and cultivation mechanism is a good way to solve the problems of tutor shortage. We can choose properly low-grade teachers with the sense of responsibility, lofty moral character and excellent professional ability for undergraduate advisors, open tutors training course, form a working group of the instructor, arrange learning capabilities, 
experienced senior tutor for young teachers, improve the mentoring to accelerate the development of young teachers.

We should make full use of modern information technology and Internet network, innovate guidance mode, build a virtual tutor system work platform, expand channels of communication with students, and form a three-dimensional learning community.

We should build an evaluation system of undergraduate tutorial system with local characteristics, put emphasis on the combination of quantitative evaluation and qualitative evaluation, absolute evaluation and relative evaluation, dynamic evaluation and static evaluation, self-assessment evaluation with others [8].

\section{Summary}

Under the background of Chinese intelligent manufacturing, the introduction of tutor system education model in applied local universities is of great significance for strengthening students' learning ability, practical ability and innovation ability. This paper analyzes the problems of insufficient teachers, shortage of funds, cultural conflicts, and imperfect management mechanism and evaluation system in the implementation of tutorial system in local colleges and universities. It puts forward some measures to reconstruct the concept of university education, maintain the basic characteristics of tutor system, modernize, localization and school-based transformation of undergraduate tutor system, and establish an effective implementation mode of undergraduate tutor system through innovation.

\section{References}

[1] Ministry of education, National development and reform commission, Ministry of finance. The guidance on ordinary undergraduate colleges and universities of practical transferring[EB/OL]. http://www.moe.edu.cn/srcsite/A03/moe_1892/moe_630/201511/t20151113_218942.html, 10.23.2015.

[2] Burton R. Clark, Explore places-modern scientific research and graduate education at the university, Zhejiang Education Publishing House, 2001.

[3] Cao Huijing, Yang Li and Ceng Hongyi, The Problem and countermeasure research on the basic standard of average appropriation fund in common colleges and universities in our country, Journal of Guangxi institute of education, vol.3, pp.28-32, 2015.

[4] Chen Hongjie, German classic university concept and its influence on China, Peking University press, pp. 60, 2002.

[5] Jiang Xifeng and Liu Xiaoqiang, Contradictions and way out: local colleges to implement tutorial system, Journal of higher education research in Heilongjiang province, vol. 5, pp.64-67, 2011.

[6] Fu Bajun, Tutorial system of exploration and practice, China's higher education, vol. 10, 2008.

[7] Li Guocang, Ought to be and the reality of the distance: Oxford tutorial system in our country development and difficulties, China's higher education research, vol. 12, pp.55-59, 2008.

[8] Ding Lin, Further promote the tutorial system in colleges and universities of the three key problems, Education research, vol. 9, 2010. 